\title{
Business Ethics, Ideology, and the Naturalistic Fallacy
}

\author{
Kenneth E. Goodpaster
}

ABSTRACT. This paper addresses the relationship between theoretical and applied ethics. It directs philosophical attention toward the concept of 'ideology', conceived as a bridge between high-level principles and decision-making practice. How are we to understand this bridge and how can we avoid the naturalistic fallacy while taking ideology seriously?

It is then suggested that the challenge posed by ideology in the arena of organizational ethics is in many ways similar to the challenge posed by developmentalist accounts of moral 'stages' in the arena of individual ethics, namely, how to account for the normative force of frameworks that are theoretically derivative yet practically essential.

I have chosen as my main theme a classical problem in philosophical ethics - the naturalistic fallacy - because I believe that business

Kenneth E. Goodpaster (A.B. mathematics, University of Notre Dame; Ph.D. philosophy, University of Michigan) has taught moral philosophy, both theoretical and applied, for the past ten years. In 1980 he joined the faculty of Harvard University Graduate School of Business Administration where, as Associate Professor, he teaches and does research on ethical aspects of organizational policy. His interests include the interfaces between ethics and psychology, biology and management studies. His publications include articles in a wide variety of journals (e.g., the Journal of Philosophy, Ethics, Environmental Ethics, Harvard Business Review), and five books: Perspectives on Morality: Essays of William Frankena (1976), Ethics and Problems of the 21st Century (1979), Values, Regulation, and the Public Interest (1980), Ethics in Mangement (1984), and Policies and Persons (1985). Work in progress includes a monograph on management and moral philosophy. ethics, even though it is a branch of applied ethics, has at its core all of the richness that philosophers could possibly seek, if only they would look and see. As a bonus, it also has all of the practical importance and urgency that philosophers so seldom seek, let alone find.

To be more precise, I should say that my theme is the roots of the naturalistic fallacy, since in the end it is the problem of justification in ethics that I want to focus on. The naturalistic fallacy is supposed to be a malady that afflicts certain kinds of arguments in ethics. Hume is often credited with having first articulated this malady when he wrote in exasperated prose about writers who:

proceed for some time in the ordinary way of reasoning and establish the being of a God, or make observations concerning human affairs; when of a sudden I am surpriz'd to find that instead of the usual copulations of propositions, is, and is not, I meet with no proposition that is not connected with an ought or an ought not. This change is imperceptible; but is, however, of the last consequence. For as this ought, or ought not, expresses some new relation or affirmation, 'tis necessary that it shou'd be observ'd and explain'd; and at the same time that a reason shou'd be given, for what seems altogether inconceivable, how this new relation can be a deduction from others, which are entirely different from it.

(Treatise, Book III, Part I, Section I, p. 469)

Hume's concern has occupied moral philosophers for centuries, and never more intensely than in the present century. And this seems appropriate, because Hume's concern carries us to the center of normative ethics by inviting critical attention to the nature of moral justification itself. In the field of applied ethics, and specifically business 
ethics, this concern becomes much more than a theoretical problem.

\section{I}

There are, I suspect, few philosophers who have tried their hands at applied ethics without in one way or another experiencing the following:

First, I survey the business scene, looking at issues like corporate social responsibility, employee rights, international business practices and the like. The issues seem compelling and above all 'relevant'. People care about the answers to questions that get posed on such topics.

Second, I turn to what I know best, the history of philosphical debate over the appropriate frameworks or principles for deriving duties, obligations, rights and virtues. I articulate these frameworks along with their inevitable and enduring pros and cons (utilitarianism, contractarianism, egoism, deontological pluralisms of various sorts, and ethical relativism).

Third, I ask myself, somewhat sheepishly, which (if any) of these frameworks or principles I (a) believe to be most justified, and (b) believe to be most relevant to resolving the issue at hand. Sometimes the order of these two is reversed. Sometimes (a) seems so difficult that I settle for an answer to (b) - any answer!

Fourth, I begin to feel uncomfortable. There seems to be a persistent and nagging 'theoreticality' about these philosophical frameworks that poisons their practicality. They seem so distant from active, daily decision-making, especially the decision-making of corporations and other key institutional 'actors' on the human stage. They seem colorless and too general, like high-level major premisses in search not only of minor premisses but of whole substrata of minor arguments. The magnitude of the 'gap' between principle and practice seems overwhelming. Too many unknown facts are missing. Too many assumptions have to be made before anything like prescription seems possible, let alone warranted.

Fifth, and finally, I turn away from these frameworks and work backwards, seeking the ideological assumptions of the main institutional players themselves, looking for strong and weak points in their lower-level normative patterns of justification. "This company seems to assume too much about private property in its environmental policies. That manager assumes that the employment relationship is fully voluntary on both sides. That corporation is behaving as if its ethics depended solely on laws and geography."

If these reflections make contact with the reader's experience, as they do with mine, then we are in a position to wonder together about the nature of moral justification in applied ethics, and specifically, about the role of what we might call the 'middle level normative patterns' that such justification often involves.

A colleague of mine, Professor George Cabot Lodge, calls these middle-level patterns ideologies'. They are frameworks of ideas

which a community uses to define values and to make them explicit. Ideology is the source of legitimacy of institutions, and the justification for the authority of those who manage them. Ideology can be conveniently seen as a bridge which a community uses to get from timeless, universal non-controversial notions such as survival, justice, economy, self-fulfillment and self-respect to the application of these notions in the real world.

('The Connection Between Ethics and Ideology', Journal of Business Ethics, May 1982.)

The metaphors of 'middle level' and 'bridging' used above are significant in several respects. First, the implication is that ideologies are somewhat more concrete and practical than the philosophical frameworks referred to earlier. Presumably this means that they are more readily available for doing ethical 'work', if I may put it in such terms. They are more directly 'invokable'. To use an example based on Lodge's discussion, it is easier to understand an appeal to property rights or the limited state than to the greatest good of the greatest number or the principle of universalizability.

Second, and more intriguing, is the implication that ideologies are somehow normative in character yet historical at the same time. That is, they are not 'timeless' frameworks whose validity is always to be assumed. They have a kind of 'life of their own'. They shift, drift, evolve, and develop.

This fact about ideologies is intriguing because it puts philosophers a little off-balance. If a principle or a normative framework is to do its proper work, we are tempted to think, it ought 
to be properly stable. Yet ideologies do not appear to be stable. So how can they have normative force? How can they truly justify institutional decision-making if they are themselves subject to the vicissitudes of change and evolution? Are ideologies really bridges in the normative realm - or are they better viewed as objects for investigation in descriptive ethics? And if the latter, then isn't their use in moral justification suspect? Aren't arguments based on appeals to ideology inevitably flawed by the naturalistic fallacy? Are the tenets of ideologies Humean oughts or Humean ises?

We seem to be confronted with a dilemma. Either we commit the naturalistic fallacy by using (rather than descriptively mentioning) ideologies as frameworks for justification in applied ethics or we abjure such 'uncriticalness' and wallow in our issue-oriented space with the minimal normative resources of our high-level philosophical frameworks. Neither alternative seems appealing. The Scylla of conventionalism is flanked by the Charybdis of irrelevance.

Now I realize I have overstated the case somewhat on both horns of the dilemma. Obviously more can be said about the normative force of ideologies and much more can be said about the (direct) relevance of philosophical frameworks (e.g., can the structure of rule-utilitarianism be invoked here?). But even if all this were said, I am convinced that something like our dilemma would remain. For the fact is that moral justification relative to an ideological 'bridge' has a double aspect. From one point of view, it is no justification at all - it is at best what we might call 'rationalization'. While from another point of view, assuming that an ideology has some higher level warrant, it seems that the higher level warrant does all the work and that ideology is but a transfer agent, mere 'popularization'.

In the time remaining to me, I want to argue that coming to terms philosophically with the phenomenon of ideology is among the most pressing challenges facing applied ethics, and especially business ethics, today. And I want further to suggest that the structure of this challenge is similar (on a macrocosmic level) to the structure of another challenge (on a microcosmic level), adding weight to some reflections that I have offered elsewhere about the 'projectability' of micro to macro levels in business ethics (see 'The Concept of Corporate Responsibility', Journal of Business Ethics, February 1983). Whether there are solutions to the problem and what they may be if there are, I will leave to the critical reader.

\section{II}

As to the importance to business ethics of a philosophical understanding of ideologies, there is perhaps no better evidence that the fact that so much of business behavior and corporate decision-making appear to be ideologically anchored. In addition to the work of George Lodge, the works of Michael Novak, Robert Heilbroner, Christopher Stone, Thomas Petit, Michael Maccoby and others (all so very different in background and discipline) make this abundantly clear. Whether one's perspective be that of politics, religion, law, economics, or psychology, the discovery is consistently that the power of certain normative patterns of reasoning over the decision-making of business executives is awesome. And it also seems to be true that the categories in which such patterns of reasoning are voiced seldom map neatly onto the standard categories of philosophical ethics.

Interestingly, all of the writers just mentioned do more than describe the importance of these patterns or ideologies in decision-making. They also suggest a shift or evolution, a dynamic (vs. static) view of the patterns of moral justification used in business life. Roughly, the shift is away from what George Lodge calls 'individualism' or the 'Lockean' ideology to a less articulate but very real 'communitarian' ideology. The marks of these two ideologies according to Lodge are (in summary form) as follows:
'THE LOCKEAN FIVE'

1. individualism

2. property rights

3. competition - consumer desire
'THE NEW IDEOLOGY'

1 '. communitarianism

2 '. rights and duties of membership

3'. community need 

4. limited state
$4^{\prime}$. active, planning state
5. scientific fragmentation $5^{\prime}$. holism - inter-
dependence

Lodge's conclusions? Sometimes they are difficult to interpret. And this difficulty is neither peculiar to Lodge's work nor unpredictable philosophically. The temptation, obviously, is to treat the 'new' ideology as somehow normatively more acceptable as a justificatory framework for moral reasoning, so that not only does the transition (from old to new) represent a change, but a change for the better. Yet 'ideological analysis' (by whatever name) is not supposed to be normative; it is supposed to be descriptive: "How can we preserve and protect some of the most cherished attributes of the old as we move inexorably toward the new?" (op. cit., p. 97). Heilbroner expresses similar sentiments (see references below).

This sounds like the shift from old to new is in some ways (a) unavoidable and (b) unfortunate. Hardly normative. The trouble is that in as many places, we hear a different message: "The old notions of managerial authority rooted in property rights and contract no longer seem to be acceptable", and "the traditional ideology of America, that of Hardin's plainsman, has become inconsistent with the real world... Corporate America has outgrown the ideology to which it and the community generally have traditionally looked for its legitimacy..." Finally:

We are thus looking for legitimacy and authority to ideas which are increasingly inconsistent with practice and reality. Theoretically, there are two possibilities: (1) returning to the old ideology, making practice and reality conform, or (2) recognizing explicitly the new ideology and making the best of it, aligning our behaviour with it, hopefully preserving what is most valuable of the old. As a practical matter, the first choice is impossible. We must do the second. Until we do so institutions will lack legitimacy; the powerful will be drained of authority; the definition of values will be unclear and what many consider unethical behavior will abound. (pp. 8687)

The ambivalence that I hope I am not reading in to this text, over the descriptive versus prescriptive force of ideology and ideological change is, philosophically, very important. It signals the Scylla and Charybdis problem mentioned earlier, and ultimately an awareness of the problem of justification in applied ethics.

And whether the categories be Lodge's 'New American Ideology', Novak's call for a new defense of 'democratic capitalism', Heilbroner's talk of the decline of 'business civilization', Stone's remarks about the need for a shift in 'corporate culture', Petit's talk of a 'moral crisis in management', or Maccoby's reflections on a new business 'psychostructure', the underlying challenge remains: How can we achieve a philosophically clear understanding of the normative status or force of this middle-level phenomenon we are calling ideology? How can we use this 'bridge' concept without either losing its value or falling victim to its seductively fallacious implications? I submit that this question should be high on the agenda of business ethics in its current phase.

\section{III}

My concluding remarks will be methodological. I simply want to suggest that the problem or challenge I have outlined above bears strong resemblance to another cluster of problems on a different level. Those who have read some of my recent work on corporate responsibility will know that I emphasize the analogy between the individual person and the corporation in trying to shed light on business ethics. I have called this the 'principle of moral projection', and I have argued that it affords useful insights into both personal morality and organizational policy. If this principle makes any sense, however, we should expect not only that it will shed light from the level of individuals to the level of organizations. We should also expect that it will, as it were, 'shed darkness' as well. That is, we should expect that particularly difficult issues on the one level will find their particularly difficult analogues on the other.

In our present context, we should expect an individual or personal analogue to the problem 
of moral justification and ideology that we have previously described on the level of institutional action-guidance. And so we do.

In an article in Ethics ('Kohlbergian Theory: A Philosophical Counter-invitation', April 1982), I argued that it was important to remind ourselves of the limits of descriptive or explanatory 'stage' theories of human moral development. Lawrence Kohlberg, as many are aware, is concerned to map the development of individuals along a series of stages and in a certain sequence, roughly from egoistic hedonism through rule-obedience to autonomous utilitarian or Kantian moral reasoning.

It is not my purpose here to reiterate either my difficulties or my delight with this apparently descriptive ethical (empirical) program, but I do want to underscore the similarities between this effort and the efforts at doing ideological analysis' that we have been discussing. And these similarities extend quite generally to other 'developmentalist' or 'evolutionary' approaches to human character, whether careful and systematic (like Kohlberg's) or sloppy and popmarket-oriented (the reader can supply some titles).

It is tempting, as we have seen, to begin such accounts with an innocent and uncontroversial descriptive-explanatory purpose, and slowly, by degrees, because of an underlying and presupposed approval in author and audience for 'later' over 'earlier' stages, to slip into normative claims where only descriptive claims have been warranted.

How and why does this happen? There are several explanations, but certainly among them is the nearly universal attitude that we share about the process of 'development' itself. Growth is good - who could be against it? Progress is good - who could oppose it? Evolutionary change is good - more power to it. 'Stages' or 'phases' are almost automatically assumed to come with 'later is better' written in to their inner logic.

As soon as we point this out to ourselves, however, the challenge becomes apparent: the naturalistic fallacy pursues us. On the one hand we know that if we are headed for 'ought', there is no other path than via 'is'. Yet on the other hand, we know that the path must be walked with incredible care. Whatever else 20 th century may have taught us, it has taught us that we cannot 'back into' or 'stumble into' oughts from ises, as if by magic or accident.

Kohlberg, and his followers in developmental psychology (like some of those who do ideological analysis on the macro level?) do not always keep this caution in mind, even though such paper titles as 'How to Commit the Naturalistic Fallacy and Get Away With It?' (Kohlberg in Mischel (ed.), Cognitive Development and Epistemology, Academic Press, New York, 1971) seem to suggest that they do. Too often, in my opinion, their work fails to be sufficiently critical at just the points where it becomes most practical, e.g., where later stages are recommended over earlier stages, where the 'last' stage is defined, and where questions of clinical intervention are pursued.

The key words are 'critical' and 'practical'. These words bring us to the very center of applied philosophy and applied ethics in particular. Practicality demands that we keep our eyes and ears attentive to the actual middle-range frameworks of decision-makers themselves, that we allow ourselves to take 'ideology' seriously. Criticality demands with equal intensity that we not be carried off into evolutionary inevitabilities or magical 'unfoldings' to the point where our own responsibilities to guide such change are overlooked. Determinism (whether of the happy or of the sad variety) is the enemy of honest normative inquiry.

I suggest that the philosophical issues surrounding Kohlberg's work on the individual or micro level, via the principle of moral projection, are analogous in many ways to the issues surrounding ideological analysis on the institutional or macro level - and that they are just as difficult, pointing as they do to a similar problem about the nature and normative force of middle-level, practical reason in the moral life. And I apologize, but not too abjectly, for leaving the problems with the reader rather than solving them. But the truth is that I am not sure I know how. 


\section{Postscript}

As the field of business ethics (and applied ethics generally) unfolds, new in many ways, it behooves us to recognize that certain tried and true philosophical investigations not only still apply, but apply with special importance. For in our enthusiasm over the new, we may be tempted to lose sight of what was rich in the discipline of the old. In our newfound concern for the moral dimensions of both business life and the business system itself, both the internal and the external aspects of business ethics, we might overlook the fact that business ethics is still a branch of ethics and subject to certain caveats as a result.

\section{References}

Heilbroner, Robert: 1974, An Inquiry into the Human Prospect, Norton, New York.

Heilbroner, Robert: 1976, Business Civilization in Decline, Norton, New York.

Kohlberg, Lawrence: 1981, The Philosophy of Moral Development, Harper \& Row, San Francisco.

Lodge, George: 1979, The New American Ideology, Knopf, New York, 1979.

Maccoby, Michael: 1976, The Gamesman, Simon and Schuster, New York.

Maccoby, Michael: 1981, The Leader, Simon and Schuster, New York.

Novak, Michael: 1982, The Spirit of Democratic Capitalism, Simon and Schuster, New York.

Petit, Thomas: 1967, The Moral Crisis in Management, McGraw-Hill, New York.

Stone, Christopher: 1975, Where the Law Ends, Harper \& Row, New York.

Dept. of Mathematics, University of Notre Dame, and

Dept. of Philosophy, University of Michigan. 